\title{
Conversão de Glicerol a Aditivos de Combustíveis por Catálise com Líquido lônico sob Irradiação Micro-ondas
}

Fabio G. Zanin \& Alcindo A. Dos Santos

O glicerol, principal subproduto oriundo da produção de biodiesel em processos de transesterificação, foi convertido em diversos compostos que apresentam propriedades aditivas a combustíveis. As transformações foram assistidas por catálise com um líquido iônico (ácido de BrØnsted: metanosulfonato de $N$-metil-2-pirrolidônio), sob irradiação micro-ondas, permitindo a obtenção dos correspondentes produtos em altos rendimentos, seletividades e baixos tempos reacionais.

Palavras-chave: aditivos, biodiesel, glicerol.

Glycerol, the major transesterification biodiesel byproduct, was converted into many fuel additive compounds. The transformations were catalyzed by an ionic liquid (BrØnsted acid, $N$-methyl-2-pyrrolidonium methanesulfonate), under microwave irradiation allowing the production of these compounds in high yields, selectivity and very short reaction times.

Keywords: additives, biodiesel, glycerol. 


\section{Introdução}

Os esforços recentes na busca de fontes de energia renováveis, bem como o desenvolvimento de processos de produção de energia para substituir os baseados em fontes fósseis, têm resultado em uma enorme produção de biodiesel por todo o planeta. A transesterificação de óleos vegetais (triacilglicerídeos) é um dos mais importantes processos de produção de biodiesel, um substituinte renovável para o diesel mineral. O glicerol, principal subproduto da transesterificação de óleos vegetais, corresponde a aproximadamente $10 \%$ da massa total do novo diesel produzido ${ }^{1}$. Apesar de atualmente muitos processos alternativos de transesterificação serem conhecidos, os baseados na reação entre óleos vegetais e metanol catalisada por hidróxido de sódio ou potássio continuam sendo os mais comuns e economicamente viáveis².

De acordo com Darol Brown, presidente de uma companhia de consultoria oleoquímica americana, aproximadamente dois terços de toda a produção de glicerol no mundo vem do processo de produção de biodiesel $^{3}$. Combinadas, as produções dos EUA e da Europa em 2008 corresponderam a 1,2 milhões de toneladas, quase o triplo da produção de 2004. Desde 2005, muitas companhias por todo o planeta têm divulgado suas intenções de ampliar suas atividades para a utilização de glicerol como materiais de partida. Nesta lista, encontram-se a Dow Chemical, Solvay, Archer Daniels Midland, a joint venture entre Cargill e Ashland, Quattor, Hustsman Corporation, Linde, etc.

De acordo com especialistas e alguns pesquisadores dessas companhias, o glicerol pode ser empregado como material de partida para a produção de novas commodities, atualmente baseadas na petroquímica, tais como ácido acrílico, epicloridrina, propileno glicol, propileno, hidrogênio, metanol, carbonato de glicerina e outros ${ }^{1,3,4}$. A Glycos iniciou atividades em 2008, comercializando tecnologia para converter glicerol, por ação de micro-organismos, em ácidos láctico e succínico, 1,2-propanodiol, 1,4-butanodiol, etanol e outros compostos químicos de base. Essas últimas transformações são muito promissoras, mas de acordo com Richard Cilento, seus micro-organismos podem ser mortos por contaminantes do glicerol oriundo das companhias de biodiesel ${ }^{3}$.
Devido a essa crescente produção de biodiesel, especialmente no Brasil, toneladas e toneladas de glicerol contaminado, proveniente desses processos, têm sido produzidas e impropriamente estocadas a céu aberto acarretando em sério problema de contaminação ambiental. Dependendo do processo empregado, especialmente aqueles baseados em catálise alcalina, a qualidade do glicerol paralelamente produzido é tão baixa que processos de purificação tornam-se economicamente inviáveis e proibitivos para quaisquer operações comerciais.

Com base no que apresentamos acima, torna-se evidente a importância no desenvolvimento de processos verdes em toda a cadeia de produção de biodiesel.

Recentemente, nós desenvolvemos uma alternativa verde de produção de biodiesel etílico usando um catalisador (líquido iônico) facilmente preparado in situ, a partir de reagentes comerciais e empregando o próprio óleo vegetal como solvente 5 . Observamos que a etanólise catalisada se processa igualmente bem sob aquecimento convencional $^{5}$, assim como sob irradiação micro-ondas ${ }^{6} \mathrm{e}$ também em dióxido de carbono supercrítico ${ }^{7}$, sendo que estas duas últimas encontram grande apelo ambiental.

Através desses processos, ao final da reação, ocorre a rápida e limpa separação de fases, sendo que a de menor densidade corresponde ao biodiesel etílico e a mais densa é composta pelo glicerol e o catalisador (líquido iônico).

Como a reação de transesterificação (entre triacilglicerídeo e etanol) foi eficientemente promovida pelo catalisador (líquido iônico), imaginamos que o glicerol poderia ser convertido, por ação do mesmo catalisador, a outros compostos, também por reações de transesterificação ou de similar mecanismo.

Neste trabalho, reportamos a conversão do glicerol em diversos compostos que apresentaram ação aditiva em biodiesel, diesel e blendas destes.

\section{Materiais e Métodos}

Todos os reagentes são comercialmente disponíveis e utilizados sem tratamento adicional. As reações foram conduzidas em um aparelho de micro-ondas CEM Discover. As análises cromatográficas foram realizadas em um cromatógrafo a gás Shimadzu GC2014 acoplado a um injetor automático AOC20i e coluna DB5HT (30 m $\mathrm{x} 0,32 \mathrm{~mm} \times 0,1 \mu \mathrm{m})$. A rampa de aquecimento utilizada 
foi $40{ }^{\circ} \mathrm{C}$ (5 minutos) até $250{ }^{\circ} \mathrm{C}\left(10^{\circ} \mathrm{C} \cdot \mathrm{min}^{-1}\right)$ e posterior aquecimento até $350^{\circ} \mathrm{C}\left(25^{\circ} \mathrm{C} \cdot \mathrm{min}^{-1}, 5\right.$ minutos $)$, pressão $80 \mathrm{kPa}$ e fluxo total de $75,1 \mathrm{~mL} \cdot \mathrm{min}^{-1}$. Os tempos de retenção dos compostos são (em minutos): (1): 9,72; (4a): 9,36 e 10,46; (4b): 12,72; (4c): 13,98; (5): 9,75 ; (6): 5,67; (9a): 9,93; (9b): 9,52; (10a): 12,65; (10b): 12,49.

O líquido iônico 3 foi preparado pela adição lenta de 0,1 mol (6,54 mL) de ácido metanossulfônico a um balão de $50 \mathrm{~mL}$, em banho de gelo, com $30 \mathrm{~mL}$ de benzeno e 0,1 mol (9,72 mL) de $N$-metil-2-pirrolidona, sob agitação magnética. Após $4 \mathrm{~h}$ de reação, o benzeno foi removido sob aquecimento a 1-5 mmHg por $1 \mathrm{~h}$. Os compostos 4 a, $\mathbf{4 b}$ e $\mathbf{4 c}$ foram obtidos por reação de glicerol com acetato de etila ou ácido acético, conforme metodologias listadas no Esquema 1. O composto 5 foi obtido pela reação de glicerol com 2,2-dimetóxi-propano e/ou acetona com acetato de etila, conforme o esquema 3. O composto 6 foi obtido pela reação de glicerol com 2,2-dimetóxi-propano e/ou acetona, de acordo com os esquemas 2 e 3 . Os compostos 9a e 10a foram sintetizados através da reação do glicerol com butanal e $\mathbf{9 b}$ e $\mathbf{1 0 b}$ foram preparados pela reação do glicerol com butanal, na presença de acetato de etila, conforme esquema 4.

\section{Resultados e Discussão}

A triacetina ${ }^{8-13}$ é um composto químico de grande importância e variada aplicação, classicamente produzida por catálise com ácido sulfúrico. ${ }^{13}$ Essa substância tem sido usada em formulações de biodiesel, resultando em um combustível final com melhor desempenho a baixas temperaturas e melhores propriedades de viscosidade. Delgado e colaboradores ${ }^{9}$ descreveram o uso de acetais, derivados de glicerol, como aditivos que melhoram propriedades tais como ponto de fluidez e viscosidade quando empregados como aditivos em ésteres metílicos e etílicos de ácidos graxos.

Neste trabalho, investigamos a preparação de uma série de compostos derivados do glicerol por catálise com um líquido iônico que, em trabalhos anteriores, demonstramos ser eficiente catalisador na produção de biodiesel etílico, por transesterificação de triacilglicerídeos ${ }^{5-7}$.

Inicialmente, estudamos a conversão do glicerol na triacetina (4c) sob diferentes condições e empregando acetato de etila (2a) ou ácido acético (2b) como reagentes, por catálise com um líquido iônico (3). No Esquema 1, estão apresentados os resultados desses experimentos.

Como se pode observar, a distribuição entre os produtos mono- (4a) e di-acetilados (4b) é muito pequena em ambos os casos, com favorecimento para o produto triacetilado (4c). Com ácido acético, foi possível obter o produto de interesse em excelente rendimento, menor tempo reacional (20 minutos), menor quantidade do catalisador ( $1 / 3$ do requerido quando acetato de etila foi empregado) e uma relação estequiométrica entre glicerol e o doador de acetato de 1:2, ao passo que quando acetato de etila foi empregado como agente acetilante, a relação estequiométrica entre glicerol (1) e 2a foi de 1:66,7 para que houvesse conversão completa. Esses resultados sugerem fortemente que o ácido acético pode tanto estar agindo como reagente quanto como co-catalisador da transformação, uma vez que o líquido iônico (catalisador) age como um ácido de BrØnsted, assim como estaria agindo o próprio ácido acético.

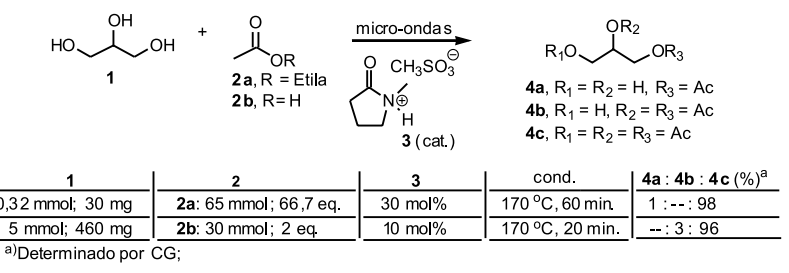

Esquema 1. Preparação da triacetina (4c) por reação de acetato de etila (2a) ou ácido acético com glicerol (1), sob irradiação micro-ondas e o catalisador 3 .

Essas reações foram conduzidas com amostras puras de glicerol e também com misturas glicerol/líquido iônico provenientes de reações de transesterificação de óleos vegetais com etanol, apresentando mesmo desempenho. Nesses casos, depois de terminada a reação de transesterificação, a fase mais densa (glicerol + líquido iônico) foi separada da menos densa (biodiesel etílico) e a ela foi acrescido quantidade apropriada do agente acetilante e submetido à reação por irradiação micro-ondas.

Terminadas essas reações, a triacetina pôde ser facilmente recuperada por extração da mistura reacional com hexano, mas visando a desenvolver processos mais práticos e que pudessem encontrar apelo industrial, conduzimos experimentos onde o próprio biodiesel foi empregado como solvente para a extração, o que resultaria em biodiesel aditivado e recuperação do líquido iônico para sua reutilização. Esse tratamento foi 
bastante eficiente uma vez que a triacetina, assim como o biodiesel, é bem menos polar que o líquido iônico.

Garcia e colaboradores ${ }^{14}$ reportaram a preparação e formulação de blendas de diesel/biodiesel com o acetalacetato 5 e demonstraram que este, isoladamente ou em associação com a triacetina (4c), confere melhorias em algumas propriedades do combustível final. Vários parâmetros foram avaliados e foi observado que o composto 5 não traz melhorias nas propriedades de refrigeração como 4c, contudo não exerce qualquer efeito negativo. Por outro lado, $\mathbf{5}$ produz efeito positivo sobre a viscosidade do combustível o que está de acordo com as exigências estabelecidas (Padrões ASTM D6751 e EN 14214) para ponto de ignição e estabilidade a oxidação de combustíveis.

Assim, decidimos investigar a conversão do glicerol ao acetal-acetato 5 sob irradiação micro-ondas por ação do catalisador 3. Em uma primeira investigação, conduzimos experimentos a fim de encontrar as condições ótimas para total conversão do glicerol no hidróxi-acetal 6, precursor do acetal-acetato 5, por reação com propanona e os resultados obtidos estão apresentados no Esquema 2.

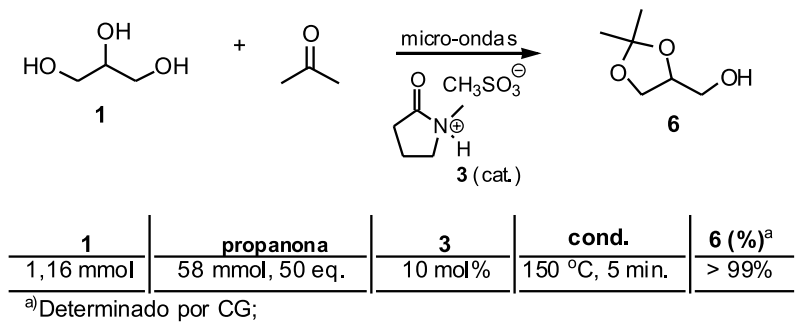

Esquema 2. Preparação do hidróxi-acetal 6 por reação de propanona com glicerol (1), sob irradiação micro-ondas e o catalisador 3.

O composto 6 foi empregado em estudos anteriores a fim de testar suas propriedades aditivas para combustíveis e embora alguns parâmetros tenham sido aceitáveis foi observado que sob as condições experimentais de análise $\left(95^{\circ} \mathrm{C}\right.$, borbulhamento de $\mathrm{O}_{2}$ a uma razão de $3 \mathrm{~L} / \mathrm{h}$ por $16 \mathrm{~h}$ ), o mesmo sofre hidrólise levando ao seu precursor, glicerol ${ }^{14}$.

Com base nisso e no bom resultado observado na produção de $\mathbf{6}$, decidimos produzir o composto 5 por reação concomitante de glicerol, reagentes doadores das funções acetal e acetila e o catalisador $\mathbf{3}$ sob irradiação micro-ondas a fim de verificar se seria possível obter diretamente o composto 5 em uma etapa reacional, conforme apresentado no Esquema 3.
O composto 5 foi produzido, exclusivamente, quando glicerol (1), acetato de etila (2a) e 2,2-dimetóxipropano (8) foram submetidos à irradiação micro-ondas por 30 minutos. Devemos chamar a atenção para a alta seletividade observada nessas condições em que apenas 2 equivalentes do reagente doador do grupo acetal (8) foi empregado em presença de 100 equivalentes de acetato de etila (2a, doador de grupo acetato), que poderia dar origem aos acetatos de glicerol (4a-4c).

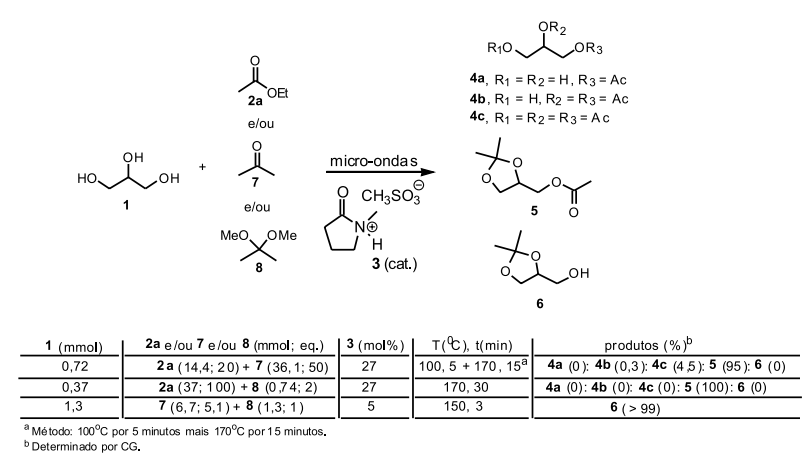

Esquema 3. Preparação seletiva do acetal-acetato 5 e do hidróxi-acetal 6 por reação de reagentes apropriados (2a e/ou 7 e/ou 8) com glicerol (1), sob irradiação micro-ondas e o catalisador 3.

Em 2010, Mota e colaboradores ${ }^{15}$ reportaram a preparação e ação anti-congelante de acetais de aldeídos alquílicos e glicerol. Dos cinco pares de acetais investigados por Mota e colaboradores, os que apresentaram melhor resultado foram os obtidos da reação entre glicerol e butanal (acetais 9a e 9b). De acordo com os autores, a adição de 5\% (vol.) dos acetais 9a e 10a ao biodiesel de gordura animal reduziu seu ponto de fluidez em $5{ }^{\circ} \mathrm{C}$. Com base nisso, decidimos investigar a transformação de glicerol em 9a e 10a por reação com butanal catalisada pelo mesmo líquido iônico. Estudos relacionados à preparação dos correspondentes acetatos também foram conduzidos e os resultados estão apresentados a seguir.

Como apresentado no Esquema 4, os hidróxi-acetais 9a e 10a foram obtidos, exclusivamente como únicos produtos, em alto rendimento e baixo tempo reacional quando a reação foi conduzida na ausência de acetato de etila. No trabalho reportado por Mota e colaboradores ${ }^{15}$, esses compostos foram obtidos por aquecimento a $85{ }^{\circ} \mathrm{C}$ durante 48 horas de reação empregando Amberlyst-15 como catalisador, em rendimento de $75 \%$. 
Quando conduzimos a reação em presença de acetato de etila (2a), os correspondentes acetatos foram obtidos como produtos majoritários e pequena quantidade da triacetina (4c) foi formada como subproduto e, nesse caso, os hidróxi-acetais 9a e 10a não foram formados. No melhor de nosso conhecimento, ainda não há relatos na literatura sobre ensaios envolvendo a utilização dos acetatos $\mathbf{9 b}$ e 10b como aditivos de combustíveis e pretendemos realizar esses ensaios em estudos em andamento em nosso grupo.

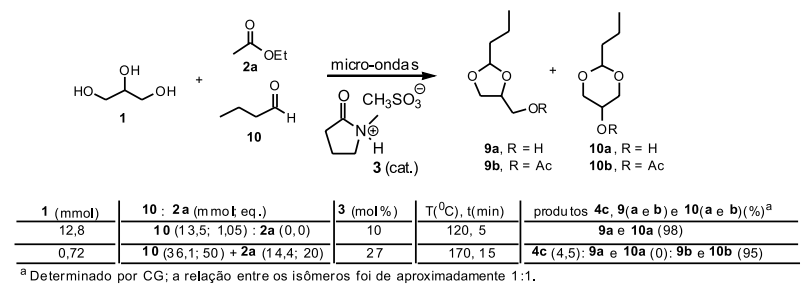

Esquema 4. Preparação seletiva dos acetais 9a e 10a e dos acetato acetais $\mathbf{9 b}$ e $\mathbf{1 0 b}$ por reação de reagentes apropriados (10 e/ou 2a) com glicerol (1), sob irradiação micro-ondas e o catalisador 3.

\section{Conclusões}

Em conclusão, demonstramos neste trabalho a fácil conversão de glicerol, um importante subproduto da cadeia de produção de biodiesel, em compostos que apresentam propriedades aditivas ao diesel, biodiesel e blendas destes. Os procedimentos desenvolvidos apresentam boa reprodutibilidade, permitem a obtenção dos produtos de interesse com alta seletividade e todos podem ser conduzidos em uma única etapa reacional, sem necessidade de etapas de purificação e/ou separação de subprodutos. Ademais, em todos os casos, não há a necessidade de manipulação de compostos tóxicos ou nocivos ao meio ambiente. Nesse particular, vale destacar que o catalisador é um líquido iônico (composto não inflamável), facilmente preparado pela simples mistura de dois reagentes comerciais. De fato, o líquido iônico pode ser preparado no próprio óleo vegetal empregado como reagente da reação de transesterificação e, ao final desta etapa, o glicerol, contendo o catalisador, pode ser diretamente empregado na produção dos compostos apresentados neste trabalho.

Dois acetais (9b e 10b) ainda não investigados como aditivos também foram preparados em uma etapa reacional com alta seletividade e suas propriedades aditivas deverão ser investigadas em nosso grupo.

\section{Agradecimentos}

Os autores agradecem ao CNPq, FAPESP, CAPES, Departamento de Química da UFSCar e ao Instituto de Química da USP-SP pelas bolsas de estudo e pelos apoios financeiro, estrutural e institucional para a realização deste projeto.

\section{Referências}

1. Takagaki, A.; Iwatani, K.; Nishimura, S.; Ebitani, K. Green Chem. 2010, 12, 578.

2. Knothe, G.; Van Gerpen, J.; Krahl, J.; Ramos, L. P. Manual de Biodiesel, Ed. Blucher, 2009.

3. Katryniok, B.; Kimura, H.; Skrzyńska, E.; Giradon, J.-S.; Fongarland, P.; Capron, M.; Ducoulombier, R.; Mimura, N.; Paul, S.; Dumeignil, F. Green Chem. 2011, 13, 1960.

4. McCoy, M. Chem. Eng. News 2009, 87, 16.

5. Macedo, A.; Wendler, E. P.; Dos Santos, A. A., depósito de patente solicitado em 30/03/2010, PI 1004396-9.

6. Zanin, F. G.; Dos Santos, A. A.; Vale, L. A. S.; Bazito, R. C., resultados ainda não publicados.

7. Zanin, F. G.; Dos Santos, A. A.; Vale, L. A. S.; Bazito, R. C., resultados ainda não publicados.

8. Li, L.; Yu, S.-T.; Xie, C.-X.; Liu, F.-S.; Li, H.-J. J. Chem. Tech. Biotechnol. 2009, 84, 1649.

9. Delgado, J. US. Pat. 0167681, 2003.

10. Wessendorf, R. Erdol Kohle Erdgas P. 1995, 48, 138.

11. Delfort, B.; Hilion, G.; Durand, I. F. R. Patent 2866654, 2004.

12. Melero, J. A.; van Grieken, R.; Morales, G.; Paniagua, M. Energy Fuel 2007, 21, 1782.

13. Maikhail, K. San, L. P. US Pat. 5777157, 1998.

14. Garcia, E.; Laca, M.; Perez, E.; Garrido, A.; Peinado, J. Energy Fuel 2008, 22, 4274.

15. Silva, P. H. R.; Gonçalves, V. L. C.; Mota, C. J. A. Bioresour. Technol. 2010, 101, 6225.

\section{Fabio G. Zanin \& Alcindo A. Dos Santos*}

Universidade de São Paulo, Instituto de Química, Departamento de Química Fundamental. Av. Prof. Lineu Prestes, 748 - Bloco 11 superior, sala 1166 - Butantã. CEP 05508-000 - São Paulo/SP, Brasil.

*e-mail: alcindo@iq.usp.br 